\title{
A LAW STUDENT-ORIENTED TAXONOMY FOR RESEARCH IN LAW
}

\section{Chris Dent*}

\begin{abstract}
Research methods in law are gaining much more attention than they used to. However, there have been few attempts to discuss the relationships between the different methods or to provide a theoretical basis for a taxonomy of the methods used in law. This article attempts to perform such a task. The taxonomy presented here is based on two foundations. The first is the understanding of research materials in terms of bodies of knowledge. The second is the separation of the researcher from the materials used (the method), with the constitution of the researcher being the source of two further dimensions of legal research. Those dimensions are the "approach" and the "purpose" of the research. Three methods (doctrinal, socio-legal and critical), three approaches (historical, comparative and empirical) and two purposes (descriptive and normative) are defined here with examples given of each. The goal is to lay out a straightforward description of the types of work that are caught under the umbrella of "legal research" so that students can reflect on the impact of their choices on their research. In turn, this enhanced understanding of the underlying dimensions of research should facilitate more effective research by law students.
\end{abstract}

\section{INTRODUCTION}

A significant literature has developed around the nature of legal research and the use of research methods in law. Much of the work operates as compilations of individual authors contributing their insights into a specific research method in law. ${ }^{1}$ There have been few attempts to discuss the relationships between the different methods or to provide a theoretical basis for a taxonomy of the

* Associate Professor, School of Law, Murdoch University.

1 See for example Dawn Watkins and Mandy Burton Research Methods in Law (Routledge, London, 2013). 
methods used in law. ${ }^{2}$ This article attempts to perform such a task. ${ }^{3}$ The value in this project is in offering to law students, predominantly, a simple schema to adopt when considering the choice of materials to use in a piece of research. It does not offer, therefore, a set of rules to be applied; instead it is aimed at being an introduction to the current, and potential, range of legal research. ${ }^{4}$ Furthermore, there is an engagement with the approach and purposes of the person choosing the material and how they interact with the available methods. The goal of the article, then, is to highlight the interaction of source material and the intentions of the researcher in order to demystify the research process to students. $^{5}$

The taxonomy presented here is based on two foundations. The first is the understanding of research materials in terms of bodies of knowledge. ${ }^{6}$ The second is the separation of the researcher from the materials used, with the constitution of the researcher being the source of the approach and the purposes of the research. Of course, the researcher makes decisions around the material used in the research; the separation here, however, focuses on the characterisation of the material (for the method) and the (constrained) choices of the researcher (for the approach and purpose). This distinction, not found in all other assessments of legal research methods, reinforces the division, in practice, between the research question (with its motivations) and the processes undertaken by the researcher to answer that question. ${ }^{7}$

2 Note, however, Terry Hutchinson and Nigel Duncan "Defining and Describing What We Do: Doctrinal Legal Research" (2012) 17 Deakin LR 83 at 113-118; and Theunis Roux "Judging the Quality of Legal Research: A Qualified Response to the Demand for Greater Methodological Rigour" (2014) 24 Legal Education Review 173 .

3 This article, therefore, may be seen to be inspired by the recent rise in interrogations of the nature of legal research - see for example Susan Bartie "The Lingering Core of Legal Scholarship" (2010) 30 Legal Studies 345 - but does not seek to provide a new insight of what legal research should be seen to be.

4 An allied purpose is to offer a response to assist those "[l]egal researchers [who] have always struggled to explain the nature of their activities to colleagues in other disciplines [or to students]": Paul Chynoweth "Legal Research" in Andrew Knight and Leslie Ruddock (eds) Advanced Research Methods in the Built Environment (Wiley-Blackwell, Chichester, 2008) 28 at 28. An alternative approach to this struggle is the exploration of law as an academic discipline: see for example Susan Bartie "Towards a History of Law as an Academic Discipline" (2014) 38 MULR 444.

5 The question of the quality of legal research is a different issue. For a recent discussion of this, see Roux, above $\mathrm{n}$ 2. It should be noted that Roux does offer a taxonomy of legal research in his discussion of the quality of research.

6 Of course, this is not the first time that this approach has been referred to: see for example Desmond Manderson and Richard Moir "From Oxymoron to Intersection: An Epidemiology of Legal Research" (2002) 6 Law Text Culture 159 at 179, citing Michel Foucault Power/Knowledge (Pantheon Books, New York, 1980). These authors, however, were not looking to apply that perspective to a taxonomy of legal research.

7 It should be noted that this article sees a distinction between the selection of materials (the method) and the interpretation of the materials. This is, in part, due to the fact that different materials may have different modes of interpretation available to them and a single category of material may also be able to be interpreted 


\section{RESEARCH METHODS: THE MATERIAL USED}

Research methods in law are here understood in terms of the source materials. It is a pragmatic approach to the question. It is also an approach that accords with Flyvbjerg's observation that "methodology is a concrete practical rationality". ${ }^{8}$ Expressed differently, it views the classification of methods as a heuristic - as the adoption of techniques that simplify the decision-making processes of researchers around the material they should use when making their arguments. More specifically, it is an approach that allows the division of methods into three groups: doctrinal, socio-legal and critical. $^{9}$

\section{A Existing Understandings of "Method"}

It is clear from the focus on source materials that the understanding of legal research methods does not have the level of specificity of the more widely accepted "scientific method". That method is: ${ }^{10}$

... commonly represented as ideally comprising some or all of (a) systematic observation, measurement, and experimentation, (b) induction and the formulation of hypotheses, (c) the making of deductions from the hypotheses, (d) the experimental testing of the deductions, and (if necessary) (e) the modification of the hypotheses ...

That said, there is a connection between the understandings of the two methods - both involve a focus on the practices adopted by the researcher. The practices for scientists are a little more in-depth; however, the selection of materials by legal researchers also amounts to a set of practices. The practices of legal researchers relate to the bodies of knowledge within which the material they use sits.

A technical understanding of a body of knowledge is available from the work of Michel Foucault, notably his Archaeology of Knowledge. In that book he discusses "discursive formations" in terms of the "rules of formation" and of the "dispersion" of statements within a body of knowledge. ${ }^{11}$ So, for

differently. As importantly, discussions of interpretation involve the third stage of the research process analysis - and this article focuses on the first two stages: the setting of the question (approach and purpose); and the selection of material (method). The issue of the analysis of the material, including its interpretation, is, therefore, outside the scope of this taxonomy.

8 Bent Flyvbjerg Making Social Science Matter: Why social inquiry fails and how it can succeed again (Cambridge University Press, Cambridge, 2001) at 29.

9 A specific alternative approach that takes an almost trans-disciplinary approach that references Flyvbjerg's empirical work is B Murphy and J McGee "Phronetic legal inquiry: An effective design for law and society research?" (2015) 24 GLR 288. This approach, however, may be too in-depth to be of value to students.

10 Oxford English Dictionary "scientific method, n." <www.oed.com>.

11 Michel Foucault Archaeology of Knowledge (Routledge, London, 1994) at 38. 
him, a given body of knowledge is governed by these rules, or practices, of dispersion; with these rules also impacting on how new statements in the formation may be brought into existence. The law is easily seen as such a body of knowledge, specifically if case law is focused upon. Only certain people are entitled to write judgments, there are specific practices associated with their production (notably the doctrine of precedent) and some judgments are deemed more important than others. ${ }^{12}$

Of course, law is not the only such body of knowledge. Foucault highlights medicine and economics. ${ }^{13}$ Many others exist. Where there is a profession or an academic discipline with a core set of practices (or a core set of "Truths" or texts) and where there is a hierarchy of experts that have a greater say about these practices, then there is a body of knowledge. ${ }^{14}$ The important thing here is that most academic writing falls within a specific body of knowledge and, to be acknowledged by that body of knowledge, a publication has to comply with the rules of that discipline. ${ }^{15}$ Many forms of legal research, however, appear to operate as an exception to this understanding. Leaving aside for the moment doctrinal research, the rules of formation of legal research are not clear cut. This may be one of the reasons why legal academics have a difficulty in discussing methods. That said, in many cases, socio-legal and critical legal researchers import the rules from other disciplines and there are enough outlets that accept these practices as legitimate forms of research to the extent that there now may be seen to be a socio-legal body of knowledge. ${ }^{16}$

Before the details of the three methods are considered here, there is value in comparing the understanding of this understanding of methods with those of other authors. One analysis is offered in the 1987 Pearce Report. The report considered the categories of research contained in the earlier, Canadian, Arthurs Report ${ }^{17}$ with those categories being "doctrinal research", "reform-oriented

12 For a more complete discussion of this, see Chris Dent and Ian Cook "Stare Decisis, Repetition and Understanding Common Law" (2007) 16 GLR 131.

13 Foucault, above n 11, at 37.

14 For an abstract discussion of the regulation of bodies of knowledge, see Michel Foucault "The Order of Discourse" in Robert JC Young (ed) Untying the Text: A Post-Structuralist Reader (Routledge \& Kegan Paul, Boston, 1981) 48.

15 This is one of the (unspoken) aspects of the peer-review process. For an article to be accepted by a peerreviewed journal, its author had to exhibit the right practices of that discipline.

16 An exploration of how legal research came to embrace practices from other disciplines is outside the scope of this article. That said, it should be noted that it is basically academic law that has accepted this research - the law, as represented by judicial decisions, is still much more limited in the types of research in which it is interested.

17 Social Sciences and Humanities Research Council of Canada Law and Learning: report to the Social Sciences and Humanities Research Council of Canada by the Consultative Group on Research and Education in Law (1983). For a contemporary critique of the report, see Leon Trakman "Law and Learning. Report of the Consultative Group on Research and Education in Law, Social Sciences and Humanities Research Council of Canada" (1983) 21 Osgoode Hall LJ 554. 
research", "theoretical research" and "fundamental research". ${ }^{18}$ The Pearce Report had reservations about the overlap between the categories and settled, for the purpose of analysing the research carried out in Australian law schools, on the categories of doctrinal, reform-oriented and theoretical research. ${ }^{19}$ Issues that persist with respect to either the Pearce Report or the Arthurs Report division are three-fold. First, there is still the issue of overlap. Secondly, this taxonomy appears based on the purposes of the research and not on how it is carried out and, therefore, arguably not about the methods of research. And finally, it is based on a division between "in law" research (doctrinal) and "about law" (the other categories). ${ }^{20}$ This dichotomy has no clear basis beyond the separation of the research lawyers do (in law) and the research others do (about law).

A second example of a taxonomy is that of Aarnio. ${ }^{21}$ His work on understanding legal reasoning is dense and thorough; ${ }^{22}$ so, the summary offered by Murphy and McGee will suffice here. These authors summarise Aarnio as asserting three methods of legal research other than doctrinal research (his key area of interest). Those three methods are "sociologies", "histories" and "comparative law".23 Murphy and McGee have concerns about the rigidity of Aarnio's division; it may, instead, be that the boundaries are not clear enough - with the comparative method being classified as a "'fusion' of methods". ${ }^{24}$ One further limitation of Aarnio's work is that, similarly to the Pearce Report, it is unidimensional and, therefore, conflates several decisions of the researchers into a limited number of categories.

To be clear, the analysis in the present article is not meant to suggest that the taxonomies of others are wrong. They may be internally consistent and be of value to other academics who are interested

18 Dennis Pearce, Enid Campbell and Don Harding Australian Law Schools: A Discipline Assessment for the Commonwealth Tertiary Education Commission (Australian Government Publishing Service, Canberra, 1987) at 9.9-9.12 [Pearce Report].

19 At 9.15. The engagement here with the choice of the report's authors is not intended to be a criticism. They were producing a piece of research for a particular purpose and for a particular audience. Their choice of categorisation of research was sufficient. It is not, however, particularly useful for instructing students about legal research (the purpose of the present article).

20 At 9.11 .

21 A third example is that of Roux, above n 2. He uses the categories "doctrinal", "socio-legal", "law and research", "comparative", "legal philosophy" and "critical". His use of the terms "doctrinal", "socio-legal" and "critical", unsurprisingly, does not match their use in this article. This is, in part, due to his inclusion of social science research that focuses on the law, rather than just considering the work of legal academics and law students.

22 See for example Aulis Aarnio Reason and Authority: Treatise on the Dynamic Paradigm of Legal Dogmatics (Dartmouth, Aldershot (UK), 1997); and Aulis Aarnio Essays on the Doctrinal Study of Law (Springer, Dordrecht, 2011).

23 Murphy and McGee, above n 9, at 298.

24 At 298 
in understanding how law may be researched. They, however, may not be so useful for those who are just beginning to learn the ropes of legal research. The taxonomy offered here allows, through the separation of "methods" from "approaches" and "purposes", a description of legal research that is separated out in terms of the decisions that a researcher makes. This, therefore, should be of greater value to students.

\section{B Legal Research Methods}

As stated above, there are three broad forms of legal research methods. ${ }^{25}$ Other methods, notably specific empirical methods drawn from the social sciences, ${ }^{26}$ may be used; however, as will be discussed below, they are better understood in terms of the empirical approach, rather than the individual legal methods. The first legal method, the doctrinal, focuses on the law as a complete body of knowledge. The other two can be seen as interdisciplinary, with the socio-legal and the critical methods being informed by different disciplines and multiple disciplines being available to researchers who adopt one of the two methods. All of the methods will be explored with reference to examples of their use. There is no suggestion that they are the best examples; however, they are all research outputs that exhibit the practices that define one of the methods.

\section{Doctrinal}

The doctrinal legal method is the most well-understood of the legal research methods; in part, no doubt, due to its links with the problem-solving method that is at the heart of legal instruction. As such, it is also the method that is taught to all law students though it may not be explicitly presented to them in terms of methodological rules to be learnt. The strength of this method comes from the (constitutive) power of the doctrine itself. ${ }^{27}$ For Hutchinson and Duncan the method is simply about "locating 'the law' or doctrine and then analysing the texts". ${ }^{28}$ It is basically an internal, or intra-

25 It may be noted that one text considers that there are three "approaches" to methodology in the social science research: "positivist", "interpretive" and "critical" and there are commonalities between that taxonomy and the one presented here. A clear difference, however, is that the authors separate out "feminist" and "postmodern" approaches from the other three, suggesting that those two approaches are in their infancy. See generally W Lawrence Neuman Social Research Methods: Qualitative and Quantitative Approaches (5th ed, Allyn and Bacon, Boston, 2003) at ch 4.

26 These methods include the use of interviews and surveys, or the interrogation of legal databases. For a recent book that covers relevant empirical methods, see Frans L Leeuw and Hans Schmeet Empirical Legal Research: A Guidance Bookfor Lawyers, Legislators and Regulators (Edward Elgar Publishing, Cheltenham, 2016).

27 This characterisation allows for an acknowledgement of the normative context of the law (a key aspect of Murphy and McGee's criticism of Aarnio, above n 9, at 299) without having that acknowledgement limit the value of doctrinal research's contributions to the understanding of the law as a doctrine.

28 Hutchinson and Duncan, above n 2, at 116. For Roux, above n 2, at 174, "doctrinal research is aimed at the systematisation and critique of a defined body of positive law ... that is offered as a participant act in the legal 
disciplinary, method of research as it has, as its focus, other legal documents. That is, it uses the law and legal commentary to answer questions about the law.

More specifically, doctrinal research focuses on the law as a doctrine - the statements of the law are seen as being important because they reflect the law. As a result, the method is defined by its emphasis on primary legal material (for example, cases and legislation) and on secondary material that can also be understood to be doctrinal research. The process of referring, predominantly, to legal texts enables a doctrinal researcher to make stronger claims about the law. The more legal, or doctrinal secondary, material is used to bolster the researcher's argument, the more likely that a legal academic or lawyer will be swayed by that argument. Importantly, however, this focus on legal material means, necessarily, that the method cannot say anything about the non-legal issues that relate to the law.

An example of doctrinal research is an article entitled "Australian cruise ship passengers travel in legal equivalent of steerage". ${ }^{29}$ The author discusses or cites 10 cases in the article, along with six statutes, one Bill, two international conventions, two protocols and one set of European Union regulations. Lewins also refers to more than a dozen secondary sources, the bulk of which are legal publications that, themselves, focus on a doctrinal analysis of the law in question. Some statistics are raised to justify the legal research, but they are not used as part of the argument of the article. It is, predominantly, a piece of research that interrogates the law and that uses other statements about the law to make its case. It may also be noted that the journal in which the article was published was the Australian Business Law Review - a journal that has a clear focus on practitioners, an audience that wants doctrinal research that is of relevance to their daily work.

There is one special case of doctrinal research that can be highlighted and that is research into legal theory. There is, of course, a wide range of research that is carried out in the area of jurisprudence; ${ }^{30}$ and many introductory textbooks in the area engage with that range. ${ }^{31}$ As such, the other two methods can also be applied to research in legal theory; however, it is sufficient to explore this area of research in terms of the doctrinal method. For legal theory research, the doctrinal primary material that is at the heart of the method is the work of the leading theorists in that area. So, instead of cases, a researcher who is examining a natural law theory may take as their primary material the

system". The latter clause of the quote is aimed more at academics and practitioners than students and reflects their desire to further the understanding of that area of law more generally.

29 K Lewins "Australian cruise ship passengers travel in legal equivalent of steerage - considering the merits of a passenger liability regime for Australia" (2010) 38 ABLR 127.

30 For some, there is a distinction between the areas of knowledge of "legal theory" and "jurisprudence". That distinction, too nuanced for the purposes of this article, is an approach supported by some textbooks: see for example James E Penner, David Schiff and Richard Nobles (eds) Introduction to Jurisprudence and Legal Theory: Commentary and Materials (Oxford University Press, Oxford, 2002).

31 See for example Augusto Zimmerman Western Legal Theory: History, Concepts and Perspectives (LexisNexis Butterworths, Chatswood (NSW), 2013). 
work of Thomas Aquinas, whereas someone interested in the positivist school may focus on the work of HLA Hart. As with the broader doctrinal method, such researchers would also refer to secondary sources that also considered the work of Aquinas and Hart respectively.

Smith's article "Has Raz Drawn the Semantic Sting?" is a useful example here. ${ }^{32}$ As is clear from the title, the author focuses on the work of Joseph Raz - a 20th century legal positivist philosopher. Smith refers to specific passages from Raz's publication "Two Views of the Nature of the Theory of Law" more than thirty times. He also refers the work of Ronald Dworkin, another legal philosopher, about 15 times in order to establish what is meant by the "semantic sting". This article is an example of almost pure theory in that there are very few references to other secondary materials - Smith just focuses on the work of Raz and Dworkin. ${ }^{33}$ So, in this case, the doctrine is the body of work that has built up around the major legal positivists and the author is restricting his argument to that doctrine a younger legal philosopher discussing more established philosophers in order to develop the doctrine. $^{34}$

\section{Socio-legal}

If the doctrinal method takes the law to be self-evidently important, then the socio-legal method privileges the social context of the law. ${ }^{35}$ Given the range of disciplines that deal with the "social", there are a number of different methods that fall under the umbrella term of "socio-legal research". With respect to the broader socio-legal method, those who use it tend to adopt the method in order to critique the law. The method does not see the law as being a separate doctrine that should be analysed by itself; instead, this method understands the law as being a "function" of society. There are, of course, multiple "contexts" to the law. There is gender, there is the economy, there is class and there is culture. Some of these have their own sub-categories - economic understandings of the law can be founded in different economic models (including mercantilist, classical, neo-classical and behavioural analyses). Each of the categories, and others (such as an analysis of law based on a non-legal ethical framework), can form the basis of socio-legal analysis. The material chosen by the researcher to carry out this type of research would, therefore, depend on which context the author was interested in. ${ }^{36}$

32 Dale Smith "Has Raz Drawn the Semantic Sting?" (2009) 28 Law and Philosophy 291.

33 Joseph Raz "Two Views of the Nature of the Theory of Law: A Partial Comparison" (1998) 4 Legal Theory 249; and Ronald Dworkin Law's Empire (London, Fontana, 1986). With HLA Hart's foundational work The Concept of Law (2nd ed, Clarendon Press, Oxford, 1994) also being mentioned: at 291.

34 So, it is much like an academic discussing a finding of the High Court in order to develop that doctrine.

35 There is, of course, significant research into socio-legal aspects of legal theory. The American Legal Realist school of thought is a clear example of this. See generally H Collins "Law as Politics: Progressive American Perspectives" in James E Penner, David Schiff and Richard Nobles (eds) Introduction to Jurisprudence and Legal Theory: Commentary and Materials (Oxford University Press, Oxford, 2002) at ch 7.

36 It may be noted that not all socio-legal researchers will be trained in a non-law discipline. At one level, this is not a problem as they are not seeking to "speak" in the other discourse - they are still, predominantly, 
Goodie's article "Toxic Tort and the Articulation of Environmental Risk" may be used as an example here. ${ }^{37}$ The author is considering the limits of tort law - a clear legal issue - in terms of one of its non-legal contexts. She uses literature from the social sciences and the humanities in order to question the way that risk is, and could be, understood by the courts when dealing with cases involving exposure to toxic materials. Despite the focus on the material from other disciplines, the research maintains its legal focus with reference to over a dozen court decisions. Goodie's analysis could have considered a similar question looking at the law's environmental context (which still would have been a form of socio-legal research); however, her use of literature produced by different bodies of knowledge broadens what she could have said about the law. A doctrinal analysis may have been limited to an exploration of the ways the judges have referred to risk, but that form of analysis could not have taken account of the more nuanced understandings of knowledge that may be found outside the legal discourse.

\section{Critical}

The critical research method goes one step further than the socio-legal methods. Instead of simply questioning the centrality of law, the critical method questions the law, the social and even the individuals that constitute both institutions. ${ }^{38}$ Examples of the method include post-structuralist, postmodern feminist and post-colonial analysis. This type of research is driven by specific theories or theorists - if the law, the society and the individuals are all subject to analysis, then there needs to be something solid upon which to base the interrogation. That solid base is the theory.

In some ways, this is the most difficult of the three methods because, to do it effectively, the researcher has to be very familiar with, if not an expert in, both the area of law and the theory they want to use. Done well, however, this type of research can be very valuable. Its effectiveness is demonstrated by the observation that, in the same way that doctrinal research is limited by its almost reification of the law as a doctrine, socio-legal research is limited by the assumptions that support the context that is explored in that research. A piece of legal research that uses the critical method questions the assumptions that underpin most socio-analysis and offers a more nuanced perspective (but one that is still limited by the constraints of the chosen theory).

writing for those with legal expertise. At another level, however, their lack of training may impact on their capacity to fully understand the texts that they are adopting.

37 Jo Goodie "Toxic Tort and the Articulation of Environmental Risk" (2008) 12 Law Text Culture 69.

38 This can be taken further, and the process of research can take into account questions relating to the role of the researcher themselves - the "attitude of the critical researcher, as opposed to the traditional researcher into 'objective' knowledge, lies in the conviction that the theorist-researcher is no mere observer or discoverer of knowledge, but is herself embedded in the social, historical, political context in which knowledge is formed": Margaret Davies "Ethics and Methodology in Legal Theory: A (Personal) Research Anti-Manifesto" (2002) 6 Law Text Culture 7 at 7, citing Max Horkheimer "Traditional and Critical Theory" in Critical Theory: Selected Essays (New York, Continuum, 2002) 188. 
To take an example of this method, there is Dent's "Relationships between Laws, Norms, Practices". ${ }^{39}$ This article considers the issue of compliance with the Road Rules using the theory of Michel Foucault. The fact that it is a critical piece is demonstrated by the questioning of the nature of the Rules as "Law" and the questioning of individuals themselves. For Dent, Foucault's theory suggests that the Rules operate as a system of norms that are internalised by members of society. The theory also sees those members to be constituted by bodies of knowledge, practices associated with bodies of knowledge and by norms. This theory, therefore, does not see individuals in society as independent agents who can "choose" to be bound by the law. Given a comprehensive acceptance of the theory requires that the researcher also acknowledge their own lack of agency, there is no external "Truth" upon which the research may be founded. In short, the research critiques the function of law in society, the relationship between the law and the individual and the extent to which the law constitutes the individual.

\section{Interplay between methods}

This is, perhaps, the key downside to emphasising the role of methods to law students. Any emphasis on the methods being discrete sets of practices encourages a concern that any piece of writing has to be one method or another. A more measured response is that one important consequence of the exceptional nature of legal research is that the methods are not absolute. That is, there are not rigid divisions between them. A doctrinal article may not lose its "doctrinality" if it refers to a small number of non-legal sources and a critical piece will not lose its "criticality" if a socio-legal work is cited in the context of fleshing out the theory. As such, a given method prescribes the material that predominantly informs the research; even the highest level of appellate courts in a jurisdiction, on occasion, refers to non-legal material without limiting the doctrinal importance of the judgment.

Of course, the test of the "predominance" of a particular class of material is vague. This lack of clarity is accentuated when it is said that a piece of research would be seen as doctrinal if it were predominantly informed by primary legal materials and secondary material that was also doctrinal. The sources cited by this secondary material would also have to pass the "predominance" test in order to be considered doctrinal, which would mean that there would be a chain of predominance testing that extended back generations.

Instead, it is possible to consider the nature of the argument that underpins the research. If the strength of that argument rests on its understanding of the law, then the article or book would be best seen as doctrinal. If, however, the research was critiquing the law on the basis of (one aspect of) its context, then it would be socio-legal. Finally, of course, if the research critiqued law, its context and the individuals, then it would be classed as critical. A cynic may suggest that this paragraph could replace the preceding 18 paragraphs. The response to that is that methods are best understood in terms

39 Chris Dent "Relationships between Laws, Norms, Practices: The Case of Road Behaviour" (2012) 21 GLR 708 . 
of practices - and not the perceived aims of authors - and so, in order to teach good methodological practice, it is best to focus on what materials a researcher should use when adopting a specific method. ${ }^{40}$

\section{RESEARCH APPROACHES AND PURPOSES: THE AUTHOR'S ROLE}

The balance of this article considers the "approaches" and the "purposes" of legal research. These are distinct from the question of method as they do not dictate which materials are used to answer the research question. Further, each approach, and each purpose, can be used in conjunction with different methods so there can be historical doctrinal research as well as historical socio-legal research; further, there can be normative doctrinal in addition to normative socio-legal research. ${ }^{41}$

\section{A Research Approaches}

The approach is the one of the three categories in this taxonomy that most closely relates to the research question. It, therefore, is closely aligned with the intention of the researcher when they carry out the research and, therefore, closely aligned to the research question at the heart of the project. ${ }^{42}$ The decision of a researcher around the approach to be taken in an article, for example, is distinct from the purpose behind the piece. This will be discussed in the next section.

With respect to a definition, the approach of a researcher, here, refers to the characterisation of the research question adopted. The three approaches highlighted are the historical, the empirical and the comparative. These are approaches, rather than methods, because they delineate the material used at a high level of generality. That is, historical research will tend to use historical documents, empirical research will generate, and analyse, empirical data and a comparative approach will use material from at least two jurisdictions. The inherent features of the approach require no more than that. Further, it may be noted that these three approaches do not cover the field of legal research. That is, there is much legal research that is not historical, comparative or empirical. In fact, it may be considered that non-historical, non-comparative, non-empirical research is the un-named norm of legal research where the questions posed by legal researchers do not suggest an answer that looks to the past, to other jurisdictions or to an exploration of how the law works in practice.

40 With respect to the doctrinal method, at least, the nature of the speaker may indicate the style of research. No matter what range of material is used to support an argument, a judgment of the Supreme Court will always be seen as doctrinal research. This may be seen in terms of the Foucaultian process of the rarefaction of speakers: Michel Foucault "The Order of Discourse" in Robert JC Young (ed) Untying the Text: A PostStructuralist Reader (Routledge \& Kegan Paul, Boston, 1981) 48.

41 Though there may be conceptual issues with normative critical legal research due to the lack of normative bases to many of the theories that could be used in this form of research.

42 It would be possible here to critique the (constrained) decisions of researchers in light of some critical theory. That, however, might limit the usefulness of this taxonomy. 


\section{Historical approach}

Unsurprisingly, a historical approach to research means that the researcher wishes to engage in the history of an aspect of the law. This aspect could be a current issue such as probing the background of a particular doctrine currently used by the courts. This can be termed, loosely, as "present-focused" history. Alternatively, the research could be aimed at understanding an aspect of the law in the past, a "past-focused" history. Obviously, this initial choice reflects the interests of the researcher. Once their decision about the target of their investigation is made, the researcher can then consider which materials - what method - they will use to investigate the issue.

An example of a past-focused socio-legal history is McLeod's work on medieval Irish law. In his chapter "Ón and airliciud", he considered the way in which that culture dealt with transfers of property between people. ${ }^{43}$ The starting point of his discussion of loans in that law was the "law tract Cáin Ónae". ${ }^{44}$ To explore the interpretation of this document, however, McLeod had to consider the social context of the law - in particular, looking at the social status of the two parties involved in the loan; the documents themselves were not enough to answer the question. Furthermore, the notion of a medieval Irish "law tract" is not the same as a statute or a judgment today. They were manuscripts of statements that had not only been glossed but also had additional commentary; ${ }^{45}$ and they were used for the training of judges and not necessarily for the determination of specific cases that came before the judges. ${ }^{46}$ McLeod's history, therefore, cannot be seen as doctrinal because the "doctrine" was enmeshed within the social context of the law - there were no statements of law separable from the culture that it sought to regulate.

One final point should be made about the historical approach. There are similarities between a present-focused historical doctrinal analysis of a particular legal test and a "plain" doctrinal analysis of the test. The latter may, for example, consider the past judgments that led up to the current test and, therefore, may be understood as a history. ${ }^{47}$ One difference between the two styles of research may simply be their scope. A history may go further back in time, or look at more material, to explore the origins of the legal test. Another example of differences in scale could be that the history may consider

43 N McLeod "Ón and airliciud: Loans in Medieval Irish Law" in Anders Ahlqvist and Pamela O'Neill (eds) Celts and their Culture at Home and Abroad (Celtic Studies Foundation, University of Sydney, Sydney, 2013) 169 .

44 At 171.

45 Fergus Kelly A Guide to Early Irish Law (Dublin Institute for Advanced Studies, Dublin, 2011) at 226.

46 At 242 .

47 This practice of looking to older cases to understand the current law may be one reason why many legal academics, the present author included, consider that they can "do" histories without any formal training in the discipline. 
the "dead ends" in legal development and not just look at the direct antecedents to the test. ${ }^{48}$ At one level, the key difference may simply be that, for one piece of research, the researcher sees themselves doing a history and, for another, they are looking to better understand the current limits of the test by exploring how it has been used in the past. This, of course, is an example of the "looseness" of methods in law; it also, however, usefully highlights the conceptual distinction between the approach taken and the method used by a researcher.

\section{Empirical approach}

The term "empirical" reflects an approach that requires the collection of data. ${ }^{49}$ The researcher will want to explore the actual impact of law on society, or the operation of law in society, and to do that, they will have to collect data on that impact. ${ }^{50}$ As mentioned above, there are a range of methods that can be adopted to collect such information. These include the interviewing, or surveying, of those who practice the law or who are impacted by the law; they also include focus groups, content analysis studies, the analysis of databases (such as those recording intellectual property rights) and the empirical analysis of documents produced during legal processes. ${ }^{51}$ As such, empirical legal research may be either qualitative or quantitative. So, "empirical" is classed as an approach as it dictates the direction of the research and does not dictate the specific material used to support the argument in any publication arising from the research (that is the task of the particular method that is used).

One example of the empirical approach is Arup and others' work into the use of restraint of trade clauses in employment contracts. ${ }^{52}$ This approach was seen to be necessary as so few restraint of trade cases make it to trial - meaning that there was a paucity of court decisions in the area. The limited number of decisions meant that any doctrinal research would be patchy (in particular, as many actions cease at the interlocutory stage, meaning, in turn, that there are few appellate level decisions). Once that approach had been adopted, a specific empirical method had to be chosen. For that publication,

48 A history of liability in negligence law may explore the 19th century courts' attempts at a test relating to the innate dangerousness of an item (such as in Longmeid v Holliday (1851) 6 Exch 761) rather than a doctrinal examination that looked at the "duty of care" and the antecedent statements around "duty" (extending back to Govett v Radnidge (1802) 3 East 62).

49 It, therefore, may be differentiated from socio-legal research that uses the empirical data found, and already published, by other researchers.

50 For a discussion, by the researchers themselves, of specific instances of this type of research, see Simon Halliday and Patrick D Schmidt Conducting Law and Society Research: Reflections on Methods and Practices (Cambridge University Press, Cambridge, 2009).

51 An example of the last category is the analysis of patent applications versus the patents that resulted from the examination, by the Patent Office, of those applications: see Andrew F Christie, Chris Dent and John Liddicoat "The Examination Effect: A Comparison of the Outcome of Patent Examination in the US, Europe and Australia" (2016) 16 John Marshall Review of Intellectual Property Law 21.

52 Christopher Arup and others "Restraints of Trade: The Legal Practice" (2013) 36 UNWSJ 1. 
the researchers interviewed 24 experienced legal practitioners to better understand the reasons for clauses to be included in contracts and the decisions around the enforcement of the clauses. ${ }^{53}$ The focus on practitioners, as opposed to parties, was both practically simpler and the interviewees could offer a perspective informed by their engagement with multiple parties. ${ }^{54}$ Surveying lawyers, or parties, ${ }^{55}$ may have produced a greater amount of data; however, the interactive nature of interviews allowed for a deeper understanding of the participants' perspectives to be gained and meant that the interviewees had significant freedom to raise any related matters of concern to them. The approach, therefore, allows insights into the operation of the law (its practical context) that cannot possibly be gained from other approaches to legal research.

\section{Comparative approach}

As indicated above, the third broad approach is the comparative approach. Law students are also often exposed to this kind of research without being given guidance as to the rules of its production. Broadly speaking, comparative research compares the law (and its context) of one jurisdiction to that of another. Such a comparison may be between multiple states within a federation (such as in Australia, the United States or Canada) or between multiple nations. Before the approach is considered in any more detail, it is worth pointing out that this is one of the few areas of legal research where there is actual debate about what it means to practice it. Given the scope of this article, however, there is little need to do more than refer to that debate. ${ }^{56}$

As it is an approach, there can be comparative doctrinal research, comparative socio-legal research and comparative critical research (though there are few examples of the last category). The underlying rationale of the approach is that, by looking at another jurisdiction: ${ }^{57}$

53 Once the interviews had been transcribed, the academics drew out themes from the material and collated the varying responses around those themes. Unsurprisingly, the themes were linked to the questions that they asked. The collated responses form the bulk of the article.

54 There would be difficulties in finding a sufficient number of litigants or potential litigants via public advertisements and, given the expertise of the interviewees, it is more straightforward to gain ethics approval for a project targeted at lawyers (there are few ways in which that population would be seen to be vulnerable).

55 There are significant issues associated with accessing litigants as participants for empirical legal research and that would not be advisable for student researchers, even at an Honours or Masters level.

56 See the discussion in Maurice Adams "Doing What Doesn't Come Naturally. On the Distinctiveness of Comparative Law" in Mark Van Hoecke (ed) Methodologies of Legal Research: Which Kind of Method for What Kind of Discipline? (Hart Publishing, Oxford, 2011) 229.

57 Geoffrey Wilson "Comparative Legal Scholarship" in Mike McConville and Wing Hong Chui (eds) Research Methods for Law (Edinburgh University Press, Edinburgh, 2007) 87 at 87. 
... it has been hoped to benefit the ... legal system of the observer, offering suggestions of future development, providing warnings of possible difficulties, giving an opportunity to stand back from one's own ... system and look at it more critically, but not to remove it from its first place in the agenda.

This understanding of the approach ties it in with the motivations of the researcher both in terms of the "hope" attached to the research and the desire to not remove the researcher's "own system ... from its first place in the agenda". Implicit in the understanding, too, is the fact that there are differences between the laws of the jurisdiction. There is much less value in doing comparative work where the laws are the same. ${ }^{58}$ Central to the approach, then, is the fact that there are identifiable differences and the assumption or hope is that exploring the differences will deepen the understanding of the researcher's own system. ${ }^{59}$

In terms of an example of comparative research, there is Young and Wikeley's article, "'Earning capacity' and maintenance in Anglo-Australian family law". ${ }^{60}$ As the name suggests, the authors compare the manner in which the laws of England and Australia treat the issue of earning capacity with respect to child and spousal maintenance. ${ }^{61}$ As such, there is a part of the article that details, for the English law, the relevant provisions of the Matrimonial Causes Act 1973, the various Child Support Acts and the case law that has developed around them. ${ }^{62}$ Following that, there is an engagement with the Australian Family Law Act 1975, the Child Support (Amendment) Act 1989 and, again, the related case law. The descriptions of the two systems were then compared with a conclusion drawn from that comparison. In this case, one author is Australian and the other English so both systems are an "own system" - nonetheless, they looked at the differing texts of each jurisdiction, found similarities and held them both to be lacking. ${ }^{63}$ There is, therefore, an implicit suggestion that the purpose of the research was to promote change.

\section{B Research Purposes}

If approach is linked most with the research question, the purpose in legal research is most closely connected to the goal, or the audience, of the research. This is the section, therefore, that has the

58 Though there is the possibility that, where the legislation is the same, the laws are applied differently in practice, opening up the possibility of comparative empirical research.

59 The quote from Wilson, above $\mathrm{n} 57$, also implies that comparative law is normative - that the research is carried out in order to optimise the law of the researcher's jurisdiction. This is not always the case. The distinction between descriptive and normative research will be discussed in the next section of this article.

60 Lisa Young and Nick Wikeley "'Earning capacity' and maintenance in Anglo-Australian family law: different paths, same destination?" (2015) 27 CFLQ 129.

61 Properly, it is the law of England and Wales that is being compared to Australian law.

62 For example, the Child Support Act 1991 (UK) and the Child Support Act 1995 (UK).

63 The final clause of the article was: "it would be appropriate for both jurisdictions to reconsider their approach to the question of earning capacity": Young and Wikeley, above n 60, at 150. 
strongest links to the findings of the Pearce Report. ${ }^{64}$ The purpose for a given piece of research relates to a researcher's motivation for undertaking the work. It can also relate to who the researcher is writing for. The purpose pre-exists the choices of how to answer the question - the approach - and which materials should be used to answer the question - the method. Of course, the research purpose is not the same as the research question. The purpose will inform the question and then the approach and the method will flow from that. To presage the two purposes discussed here, a researcher may ask "what is the law of X?" or "what should the law of X be?" Neither of these questions dictates the approach or the method; instead, they simply reflect the guiding motivation of the researcher. The two purposes considered here are "descriptive" and "normative".

\section{Descriptive purpose}

The first research purpose is the description of a given area of law or legal practice. This echoes the Pearce Report's description of doctrinal research - "a systematic exposition of the rules governing a particular legal category" - but is not limited to discussions of the law. ${ }^{65}$ Of course, a thorough analysis, using case law as the basic material, of a particular legal doctrine would be descriptive. However, socio-legal research can be descriptive as could critical research. In terms of the former, a key example is empirical research. Some empirical research is conducted for other purposes, but some is carried out just to see how the law is being used. For example, Christie and others' work into patenting strategies in the pharmaceutical sector only spoke to current practice and it made no arguments for change. ${ }^{66}$ With respect to critical legal research, given the fact that it is based on critical theories, most examples of it will be aimed at the (deeper) description of the relationships between the law, society and individuals. To refer back to Dent's work on the Road Rules, there was no attempt to suggest reforms to the Rules. The research only used the Rules as a prism through which to view the interplay of laws and norms.

Of course, simply because a piece of research is descriptive does not mean that it is simple. McLeod's work on the history of medieval Irish law describes how the law operated. ${ }^{67}$ The analysis undertaken by him - in terms of the translation of the texts, the comparison of the different law tracts and the application of the understanding of the society of the time - was highly complex. There may be straightforward overviews of the law that are more like summaries than advances in the legal body of knowledge. These, however, are less likely to appear in the better journals and may, understandably, be over-represented in the corpus of student work. To take another example, casebooks are a staple of the education of law students; these are, in effect, descriptive of the state of

64 Pearce, Campbell and Harding, above n 18.

65 Quoted in Hutchinson and Duncan, above n 2, at 101.

66 Andrew F Christie and others "Patents Associated with High-Cost Drugs in Australia" (2013) 8 PLoS 1 e60812.

67 McLeod, above n 43. 
the law in question. The level of specialist intellectual engagement with the doctrinal material renders these publications as significant works of legal research rather than a mere "description" of the law.

\section{Normative purpose}

The second research purpose is normative. Here the research is carried out in order to prompt, or support an argument for, legal change. This, of course, ties in with the "reform-oriented" research discussed in the Arthurs Report and the Pearce Report. This category is defined in the latter report as "research designed to accomplish change in the law";68 and, for another commentator, the "normative process of doctrinal analysis is the defining characteristic of most legal scholarship". ${ }^{6}$ Whilst it could be argued that a significant amount of legal scholarship is either socio-legal or critical, it is less controversial to say that much of the legal research produced is aimed at arguing for change. This could be for a change in legislation, a re-interpretation of the case law by judges or reforms to the ways in which legal processes are carried out. Few would say that the law today, and the manner in which it is applied, is perfect. The consequence of that observation is that aspects of the law or its operation could, or should, be changed. This, then, is the purpose of a great deal of legal research that is carried out these days.

In terms of the work already cited in this article, Lewins' doctrinal piece on the law relating to cruise ships sets out the current limits of liabilities in the area - specifically with respect to how the Athens Convention interacts with Australian law. Her purpose, however, was set out in the article's introduction: "It is time for the Australian Parliament to simplify the legal regime surrounding such claims and provide a basic level of protection against the more odious of the standard terms ". ${ }^{70} \mathrm{In}$ other words, Lewins was arguing for reform to the law. Further, Arup and others' research into the uses of restraint of trade clauses was empirical; however, the authors used the data they collected to argue for changes. Given the insights gained from speaking with lawyers, the authors highlighted three categories of reforms that would improve the operation of the law. ${ }^{71}$ Again, while the method was empirical, the purpose of the research was normative.

\section{CONCLUSION}

To allow a moment of reflection - this article is descriptive, non-historical, non-comparative, nonempirical and adopts a socio-legal method. It is legal research, generally, because it is written by a legal academic, on a law-related topic and published in a law journal. More specifically, it is sociolegal because it does not see legal doctrine as the predominant focus of analysis, nor is it based on a central theory that problematises the law and legal researchers. Moreover, there is no effort to posit

68 Pearce, Campbell and Harding, above n 18, at 9.12.

69 Chynoweth, above $\mathrm{n} 4$, at 37.

70 Lewins, above n 29, at 128.

71 Arup and others, above n 52, at 26-29. 
reforms, to compare the practices to those in another jurisdiction or to look at the past of legal research. Such a categorisation does not improve the value, such as it is, of the work; however, it is intended to emphasise that all legal research can be categorised and that categorisation may impact on the manner in which it is understood.

Any value in this taxonomy relates to the manner it may be used to demystify the huge range and quantity of legal research that is now available. It has been used as such to assist law Honours students to scope, and establish, their research projects and will be used for Masters students without prior research experience. ${ }^{72}$ The separation of the research process into "method", "approach" and "purpose" allows for a clearer picture of the stages of research and the relationship between the researcher and the material. Whilst this article is not a "how to" resource, the highlighted connection between the choice of material and method adopted will, hopefully, provide greater clarity around the nature of legal research, and more optimistically from this author's perspective, promote a greater engagement with non-doctrinal methods in law and law schools.

72 The running of the seminar programme that shares this taxonomy with the students has, unsurprisingly, enabled a fine-tuning of the arguments presented here. The taxonomy has also begun to be used to introduce law students, at earlier stages of their degree, to the range and function of legal research. 